\title{
Progression of myopia among medical students: A one-year cohort study
}

\author{
Agung Nugroho, Mohammad Eko Prayogo, Doni Widyandana,* Sagung Gede Indrawati, and \\ Suhardjo \\ Department of Ophthalmology, Faculty of Medicine, Public Health, and Nursing, Universitas Gadjah Mada/ Dr. Sardjito \\ General Hospital, Yogyakarta, Indonesia
}

\section{KEYWORDS}

Medical students Myopia

Myopia progression

Refractive errors
ABSTRACT Myopia is a common refractive disorder in literate countries related to education and higher occupational groups. External factors affecting myopia and its progression remain questionable. Myopia onset and progression occur during childhood and teenager. This study aimed to determine the progression of myopia and its associated factors in the medical student of Faculty of Medicine UGM, Yogyakarta, Indonesia, through a one-year cohort study. An initial observational and cross-sectional survey conducted as baseline data. Correlation calculated using Chi-square and the Spearman correlation coefficient analysis. A longitudinal cohort study conducted 12 months later to the initial survey. Myopia determined with an autorefractor without cycloplegia. BMI, intraocular pressure, and corneal curvature evaluated as factors related to progression. Five hundred five students $(98 \% ; 505$ of $515 ; 317$ from the school of medicine (SoM), 188 from the school of nursing and nutrition (SoNN)) age 15-20 years were examined. Prevalence of myopia among SoM students was $69.4 \%(n=220$ of 317$)$ and $41.4 \%$ $(n=78$ of 188 ) in SoNN. Myopia (SER $\geq-0.5$ D) found in 298 students, 81 boys (27.2\%) and 217 girls $(72.8 \%)$. Chi-square test revealed that myopia more common in Chinese than Javanese and other $(p=0.006)$ but a similar proportion in gender $(p=0.785)$ and age $(p=0.369)$. The average change of myopic progression was $-0.401 \mathrm{D}$ and $-0.094 \mathrm{D}$ per year in SoM and SoNN, respectively $(p=0.000)$. The average change of myopia of boys and girls was $-0.138 D$ and $-0.117 D$, respectively $(p=0.871)$. There was no statistically significant correlation between subjective refraction change and factors related to progression. The progression of myopia in Yogyakarta relatively similar to Western countries. Progression in the school of medicine was higher than the school of nursing and nutrition, but similar between boys and girls. No related factor correlated with the progression of myopia expects further studies.

(C) The Journal 2020. This article is distributed under a Creative Commons Attribution-ShareAlike 4.0 International license.

\section{Introduction}

Visual impairment due to uncorrected refractive error affects 200 - 250 million people in the world. Myopia is eyesight threatening disease that leads to blindness and accounts for $80 \%$ to $90 \%$ incidence in East Asia. ${ }^{1}$ Myopia is a standard refractive error in the literate countries. There is a hereditary influence on the different components of the refractive elements of the eye. However, the influence of various external factors on myopia and its progression is still under discussion. That myopia is related to education and the higher occupational groups would seem to be

*Correspondence: widyandana@yahoo.com

Departemen Ophthalmology, Faculty of Medicine, Universitas Gadjah Mada/ Dr. Sardjito General Hospital Yogyakarta,

J. Farmako, Sekip Utara, Yogyakarta 55281, Indonesia established. Accommodation, convergence, or both have most often been advanced as the reasons for these relationships. ${ }^{2}$ Myopic refractive error is the most common visual disorder affecting both children and adults in the world. It is a seemingly benign ocular disorder but tends to worsen as irreversible vision loss such as retinal detachment and macular atrophy. ${ }^{1}$

Nowadays, uncorrected refractive error is increasingly recognized as a significant cause of avoidable visual impairment worldwide, as suggested by the inclusion of uncorrected refractive error as one of the prioritized eye diseases of Vision 2020: The Right To Sight a global initiative launched by a coalition of non-government organizations of the World Health Organization. ${ }^{2}$ It is imperative to 
plan corresponding public health strategies based on the knowledge of the prevalence of refractive error worldwide through understanding its etiology, epidemiology, and various treatment regiments to modify current care as contributors to the reduction in morbidity from progressive myopia. ${ }^{3}$ However, it has a substantial social, educational, and economic impact. Myopia is one of important public health problem in Asian countries such as Taiwan, Japan, Hongkong, Singapore, including Indonesia.

It is well known that the prevalence of myopia has a significant increase globally and related to hereditary influence on the refractive elements of the eye, but environmental exposure is recognized as a major risk factor for myopia. ${ }^{4}$ This factor will lead the presence of refractive errors, such as myopia. There are several studies about factors that may contribute to the different individual variations in myopia progression. ${ }^{3}$ However, the influence of various external factors on myopia and its progression is still not well understood. ${ }^{5,6}$ As myopia has an onset and progresses in childhood, and it is important to focus research on these age groups. ${ }^{6-9}$ Prevention and healthcare planning for next-generation in decades will be much facilitated if data about this refractive error are available ${ }^{10}$.

The purpose of the study was to determine the progression of myopia and its associated factors in the medical student of Faculty of Medicine UGM, Yogyakarta, Indonesia.

\section{Method}

\subsection{Study Population}

This was a one-year cohort study of medical student batch 2012. An observational, cross-sectional survey was initially conducted. As baseline data, demographic data and clinical findings were carried out. Prevalence and demographic data were reported descriptively, correlation was calculated using Chisquare and the Spearman correlation coefficient analysis. A longitudinal cohort study was then conducted six months later. Myopia was determined with an autorefractor without cycloplegia. Body Mass Index, intraocular pressure, and corneal curvature were evaluated as factors related to progression.

\subsection{Procedures}

All the students eligible to participate had to give inform consent and fill the questionnaire then followed by eye examination including visual acuity, anterior segment examination using slitlamp, posterior segment examination using a direct ophthalmoscope, auto-refractometry, keratometry, tonometry, body weight and height examination. The corneal radius was determined with a keratometer. Intraocular pressure (IOP) was determined with noncontact tonometry.

Inclusion criteria in this study are medical students of the Faculty of Medicine UGM batch 2012 and confirm to be a subject in this study by signing the informed consent form. Exclusion criteria in this study are uncooperative subjects and subjects who suffered other eye abnormalities than refractive errors.

\subsection{Definition}

Myopia is defined as decreased visual acuity that is improved by adding negative spherical lenses with SER (spherical equivalent refraction) of -0.50 $D$ or less. Spherical equivalent (SE) was used for calculations of refractive error. The SE is derived by adding the spherical component of refraction to half of the cylindrical component.

Myopia progression is defined as the final SER reduced by initial SER. Mild, moderate, and severe myopia is defined as -0.50 to $2.99 \mathrm{D},-3.00$ to $5.99 \mathrm{D}$, and -6.00 or more, respectively.

Because there was a high correlation between the fellow eyes $(p<0.001)$, and because the results based on right eyes and left eyes were similar, data from right eyes only were reported. ${ }^{10}$

\subsection{Statistical Analysis}

The prevalence of myopia in subjects with different characteristics was expressed in percentages of the study population. The correlation was calculated using Chi-square and the Spearman correlation coefficient analysis. Myopic progression was calculated using ANOVA. All data analyses were performed with a commercial statistical software package (SPSS 16.0 for windows). 


\section{Result}

A total of 505 (98\%; 505 of 515; 317 from the school of medicine, 188 from the school of nursing and nutrition) students aged 15-20 years were examined. The prevalence of myopia among students of the school of medicine was $69.4 \%(n=220$ of 317$)$ and $41.4 \%$ ( $n=78$ of 188 ) in the school of nursing and nutrition (Table 1.). Table 1 shows the proportion of low myopia from the "school of medicine" myopia group was $59.1 \%$ ( $n=130$ of 220 ) and moderate myopia was $40.9 \%$ ( $n=90$ of 220 ). This finding was comparable to the "school of nursing and nutrition" myopia group, low and moderate myopia proportion was $67 \%$ and $33 \%$ consecutively. Chi-square test revealed that myopia was more common in Chinese than Javanese and other $(p=0.006)$, but a similar proportion in that of sex $(p=0.785)$ and age $(p=$ 0.369) (Table 2.)

In this study, IOP was not correlated with spherical equivalent refraction (Spearman correlation, $r=-0.037, p=0.413$ ) (Figure 1.). The mean IOP in students with emmetropia $(15.0 \mathrm{~mm} \mathrm{Hg})$, low myopia (14.8 $\mathrm{mm} \mathrm{Hg}$ ), and moderate myopia (15.3 $\mathrm{mm} \mathrm{Hg}$ ) were similar $(p=0.556)$. The scatter plot for the relation between IOP and refractive error of right eyes (Figure 1), emphasizes that no correlation exists (Spearman correlation, $r=-0.037, p=0.413$ ).

The difference between 2 corneal radius was correlated with spherical equivalent refraction (Spearman correlation, $r=-0.284, p=0.000$ ) (Figure 2.). The mean corneal-radial-difference in students with emmetropia (0.91), low myopia (1.06), and moderate myopia (1.47) was different $(p=0.00)$. The scatter plot for the relation between corneal radius and refractive error of right eyes (Figure 2 ), emphasizes that correlation exists (Spearman correlation, $r=-0.284, p=0.000$ ).

Another part of the study is a one-year longitudinal cohort study. All students who participated at the beginning of the study were reexamined. The total new myopic children were $2.1 \%$ of all schools in one year (Table 3 ).

Table 4 shows the average rate of myopic progression as measured by subjective trial lens examination was $-0.401 D( \pm 0.052)$ and $-0.094 D$ $( \pm 0.028)$ per year in the "school of medicine" and "school of nursing and nutrition," respectively ( $p=$ 0.000 ). This difference was statistically significant ( $p$ $<0.001$ ). There is no difference in the average change of myopia between boys and girls $(p=0.871$ ).

Table 5 presents the factors that thought had a relationship with myopia progression, including body mass index, intraocular pressure, and corneal curvature. There were no statistically significant associations between subjective refraction change and $\mathrm{BMI}$, intraocular pressure and corneal curvature, with $p$-value were $0.188,0.077$, and 0.137 consecutively.

\section{Discussion}

To our knowledge, this is the first cross-sectional and longitudinal study examining the progression of

Table 1. Demographic data

\begin{tabular}{llll}
\hline & & $\begin{array}{l}\text { School of medicine } \\
(\mathbf{n = 3 1 7})\end{array}$ & $\begin{array}{l}\text { School of nursing and nutrition } \\
(\mathbf{n = 1 8 8})\end{array}$ \\
\hline Age (years, mean \pm SD) & & $17.8 \pm 0.90$ & $18.0 \pm 0.57$ \\
Sex & Male & 117 & 18 \\
& Female & 200 & 170 \\
Race & Javanese & 200 & 169 \\
& Chinese & 51 & 5 \\
Refractive error & Other & 66 & 14 \\
& Emmetropia (-0.5D <SE<1.0D) & $97(30.6 \%)$ & $97(51.6 \%)$ \\
& Myopia (SE<-0.5D) & $220(69.4 \%)$ & $78(41.4 \%)$ \\
& Low myopia (-3.0D<SE<-0.5D) & 130 & 53 \\
& Moderate myopia (SE<-3.0D) & 90 & 25 \\
\hline
\end{tabular}

SD: Standard deviation; SE: Spherical equivalence 
Table 2. Factor associated with refractive error; proportion test using Chi-square (right eye data).

\begin{tabular}{lllll}
\hline & & Emmetropia & Myopia & p-value \\
\hline Age & 15 & 0 & 1 & 0.369 \\
& 16 & 7 & 10 & \\
& 17 & 40 & 72 & \\
& 18 & 128 & 161 & \\
& 19 & 27 & 39 & \\
& 20 & 5 & 15 & \\
Sex & Male & 54 & 81 & 0.785 \\
& Female & 153 & 217 & \\
Race & Javanese & 162 & 207 & 0.006 \\
& Chinese & 22 & 44 & \\
& Other & 33 & 47 & \\
\hline
\end{tabular}

Table 3. New cases in a one-year in each school

\begin{tabular}{ll}
\hline School & New case of myopia (\%) \\
\hline School of medicine & $7(2.2)$ \\
School of nursing and & $4(2.1)$ \\
nutrition & $11(2.1)$ \\
Total & \\
\hline
\end{tabular}

myopia in medical students, the age when growth spurt happened in human development. The last study was not focused on this specific age group. ${ }^{11,12}$ In 2007, Triharyo conducted a study on elementary school-age children. On 2013, Prayogo conducted a study to junior high school-age children. ${ }^{13}$

In this study, a high prevalence of myopia was found in students in the school of medicine. The prevalence of myopia among students of the school of medicine was $69.4 \%$ ( $n=220$ of 317 ) and $41.4 \%$ ( $n=78$ of 188) in the school of nursing and nutrition.

This study demonstrated that the prevalence of myopia in medical students was high and comparable to those in China. Shifei Wei et al. ${ }^{14}$ found a prevalence of $83.2 \%$ of myopia and $11.1 \%$ high myopia ( $S E \leq 6.0 \mathrm{D}$ ) in central Chinese university students. Not only in college students, but shanghai also had a high prevalence of myopia in preschool children. ${ }^{9}$ Similar pattern discovered in India, high prevalence refractive errors related to behavioural habits. ${ }^{15}$

We found a similar rate of myopia among boys and girls. Studies in Taiwan reported a lower prevalence and less myopic refractive error among boys. ${ }^{16}$ The proposed explanation would be that girls tend to be more diligent in writing and reading, at least at the primary school level. The subsequent increase in near-work predisposes them to myopia development. However, further studies are warranted to confirm such a proposition.

Our one-year cohort study found the new case of myopia to be $2.1 \%$. As a comparison, the study in Taiwan reported the incidence of myopia $46.7 \%$ (95\% confidence interval: $45.9,47.5 \%) .{ }^{16}$ The average change of SER for myopic children (SER $\geq-0.50 \mathrm{D}$ ) was $-0.401 \mathrm{D}$ and $-0.094 \mathrm{D}$ per year in the "school of medicine" and "school of nursing and nutrition," respectively. This significant different progression of myopia may be caused by more exposure to high technology equipment such as television, computer, laptop, cellular phone, and another device that tends to promote near work activity in the school of medicine students. ${ }^{1,8}$ Parssinen et al. reported a relationship between myopic progression and time spent on reading and close work and also between myopia and reading distance. It was assumed that time spent and close work in that of medical students (school of medicine) was higher than those in the school of nursing and nutrition. Besides, less time spent on sports and outdoor activities in childhood correlated to myopia progression in adult. ${ }^{17}$

There are many factors that may contribute to different individual variations in myopia progression. Near-work activity may be one factor related to myopia progression; objects that are viewed nearby may cause the eye to elongate further to maximize the sharpness of images on the retina. ${ }^{18}$

In this study, a similar proportion of myopia was found in both men and women. Parssinen et al. reported that progression was faster among the girls than among the boys. ${ }^{17}$ Cheng et al. reported that women had a higher prevalence of hyperopia than men. ${ }^{19}$ This may be because women's eyes have a shorter axial length and shallower anterior chamber depth than those of men, and hence a higher probability of being hyperopic.

Environmental and genetic factors have both been postulated to cause myopia. ${ }^{8}$ We hypothesized that biological measurements such as body mass index (BMI), intraocular pressure, and corneal curvature had some effect in myopia progression. 


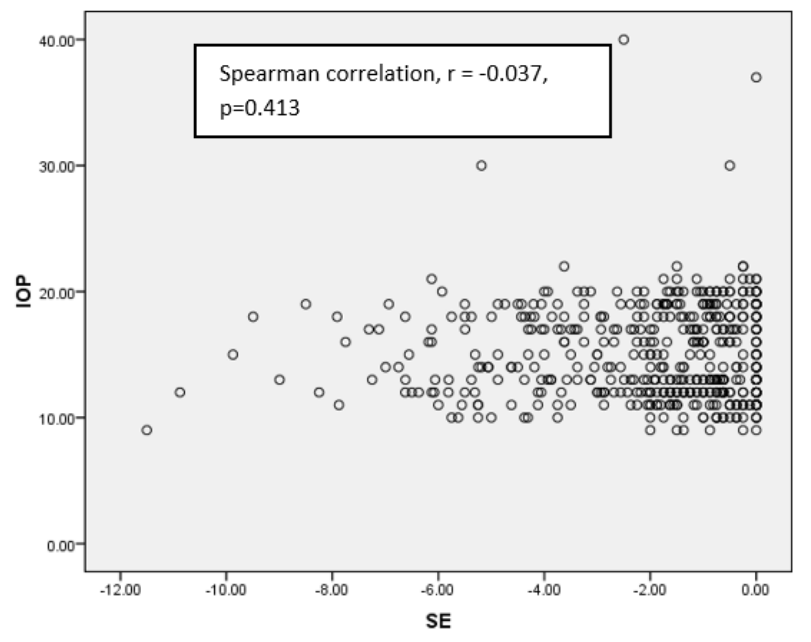

Figure 1. Correlation between intraocular pressure and spherical equivalent (right eye data).

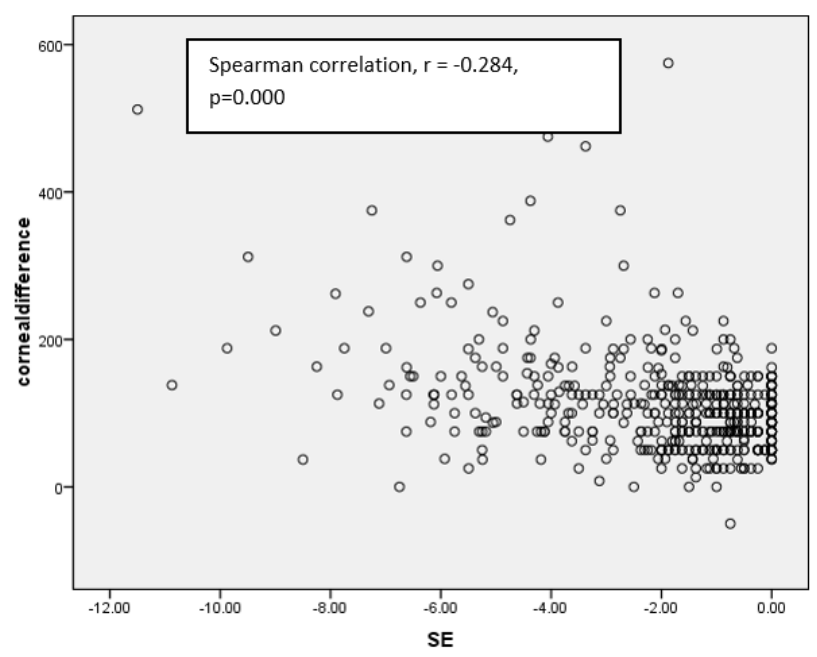

Figure 2. Correlation between difference between 2 corneal radius and spherical equivalent (right eye data).

Table 4. Progression of myopia among medical students of the Faculty of Medicine, Universitas Gadjah Mada

\begin{tabular}{llll}
\hline \multirow{2}{*}{ Area } & Myopia progression* (SD) & & \\
\cline { 2 - 4 } & Right Eye & Boys & Girls \\
\hline School of medicine & $-0.401 \mathrm{D}(0.052)$ & $-0.138 \mathrm{D}$ & $-0.117 \mathrm{D}$ \\
\cline { 2 - 3 } & & & \\
School of nursing and nutrition & $-0.094 \mathrm{D}(0.028)$ & $p=0.871$ & \\
\hline
\end{tabular}

Table 5. Factor associated for myopia progression

\begin{tabular}{|c|c|c|c|c|}
\hline \multirow{2}{*}{ Factor } & & \multicolumn{2}{|c|}{ Progression (n myopia = 298) } & \multirow{2}{*}{ p-value } \\
\hline & & Yes $(n=63)$ & No $(n=235)$ & \\
\hline \multirow{2}{*}{ Body mass index } & $>20$ & 28 & 84 & \multirow{2}{*}{0.188} \\
\hline & $\leq 20$ & 39 & 151 & \\
\hline \multirow{2}{*}{ Intraocular pressure } & $>20 \mathrm{mmHg}$ & 3 & 32 & \multirow{2}{*}{0.077} \\
\hline & $\leq 20 \mathrm{mmHg}$ & 60 & 203 & \\
\hline \multirow{2}{*}{ Corneal curvature } & High & 25 & 65 & \multirow{2}{*}{0.137} \\
\hline & Low & 38 & 170 & \\
\hline
\end{tabular}

However, our study may not find a relationship between these biological characteristics. A study about myopia and stature reported that BMI had an association with myopia. ${ }^{20}$ The Singapore Cohort Study of the Risk Factors for Myopia (SCORM) reported that there was no association between intraocular pressure and myopia progression. ${ }^{12}$ No studies reported an association between corneal curvature, the axis of astigmatism and progression of myopia. Further studies are warranted to confirm such a proposition.

In this study, IOP was not correlated with spherical equivalent refraction. Lee et al. reported findings that do not support an association between
IOP and refractive error or axial length in children. ${ }^{12}$ In Asian-Africans, but not European subjects, associations between IOP and refractive errors have been found. In white populations, the relation between IOP and refractive error or myopia has been documented.

\section{Conclusion}

The progression of myopia in Yogyakarta was relatively similar to Western countries. Progression in the school of medicine was higher than the school of nursing and nutrition, but similar between boys and girls. No related factor had an association with the progression of myopia warrants further studies. 


\section{References}

1. Wu PC, Huang HM, Yu HJ, Fang PC, Chen CT. Epidemiology of myopia. Asia-Pacific Journal of Ophthalmology. 2016;5:386-93.

2. IAPB. VISION 2020: The Right to Sight - IAPB. England; 2020.

3. Cooper J, Tkatchenko A V. A review of current concepts of the etiology and treatment of myopia. Eye Contact Lens. 2018;44(4):231-47.

4. Holden BA, Fricke TR, Wilson DA, Jong M, Naidoo KS, Sankaridurg $P$, et al. Global prevalence of myopia and high myopia and temporal trends from 2000 through 2050. Ophthalmology. 2016;123(5):1036-42.

5. Bowrey HE, Zeng G, Tse DY, Leotta AJ, Wu Y, To CH, et al. The effect of spectacle lenses containing peripheral defocus on refractive error and horizontal eye shape in the guinea pig. Investig Ophthalmol Vis Sci. 2017;58(5):2705-14.

6. Sun JT, An M, Yan XB, Li GH, Wang DB. Prevalence and related factors for myopia in school-aged children in qingdao. J Ophthalmol. 2018; 9781987.

7. Saxena R, Vashist $P$, Tandon R, Pandey RM, Bhardawaj A, Gupta V, et al. Incidence and progression of myopia and associated factors in urban school children in Delhi: The North India Myopia Study (NIM Study). PLoS One. 2017;12(12).

8. Kathrotia RG, Dave AG, Dabhoiwala ST, Patel ND, Rao P V., Oommen ER. Prevalence and progression of refractive errors among medical students. Vol. 56, Indian Journal of Physiology and Pharmacology. 2012. p. 284-7.

9. Li T, Zhou X, Chen X, Qi H, Gao Q. Refractive error in chinese preschool children. Eye Contact Lens Sci Clin Pract. 2019;45(3):182-7.

10. Chen M, Wu A, Zhang L, Wang W, Chen X, Yu X, et al. The increasing prevalence of myopia and high myopia among high school students in Fenghua city, eastern China: A 15-year population-based survey. BMC Ophthalmol. 2018;18(1).

11. Rasmiyati WP, Suhardjo. Progresifitas miopia pada siswa sekolah menengah pertama di pedesaan dan perkotaan di yogyakarta. 2015. Tesis Kedokteran Klinis. Fakultas Kedokteran,
Kesehatan Masyarakat, dan Keperawatan, Universitas Gadjah Mada.

12. Lee AJ, Saw SM, Gazzard G, Cheng A, Tan DTH. Intraocular pressure associations with refractive error and axial length in children. $\mathrm{Br} J$ Ophthalmol. 2004 Jan;88(1):5-7.

13. Prayogo $M$, Indrawati $S$, Suhardjo. Progression of myopia in the junior high school-age children: The Jogjakarta Eye Study. 2013. Tesis Kedokteran Klinis. Fakultas Kedokteran, Kesehatan Masyarakat, dan Keperawatan, Universitas Gadjah Mada.

14. Wei $S$, Sun $Y$, Li S, Hu J, Yang $X$, Lin $C$, et al. Refractive errors in university students in central China: The anyang university students eye study. Investig Ophthalmol Vis Sci. 2018;59(11):4691700.

15. Kshatri J, Panda M, Tripathy R. Prevalence, progression and associations of corrected refractive errors: a cross-sectional study among students of a Medical College of Odisha, India. Int J Community Med Public Heal. 2016;291620.

16. Guo YH, Lin HY, Lin LLK, Cheng CY. Self-reported myopia in Taiwan: 2005 Taiwan National Health Interview Survey. Eye. 2012;26(5):684-9.

17. Pärssinen $\mathrm{O}$, Kauppinen $\mathrm{M}$, Viljanen $\mathrm{A}$. The progression of myopia from its onset at age 8-12 to adulthood and the influence of heredity and external factors on myopic progression. A 23-year follow-up study. Acta Ophthalmol. 2014;92(8):730-9.

18. Huang HM, Chang DST, Wu PC. The association between near work activities and myopia in children - A systematic review and meta-analysis. PLOS ONE. 2015;10.

19. Cheng CY, Hsu WM, Liu JH, Tsai SY, Chou P. Refractive errors in an elderly chinese population in Taiwan: The shihpai eye study. Investig Ophthalmol Vis Sci. 2003;44(11):4630-8.

20. Lee DC, Lee SY, Kim YC. An epidemiological study of the risk factors associated with myopia in young adult men in Korea. Sci Rep. 2018;8(1) 